\title{
Phytochemical study, phenolic profile and antigastric ulcer activity of Morus macroura Miq. fruits extract
}

\author{
E. K. Farrag ${ }^{1}$, M. E. S. Kassem², D. Bayoumi ${ }^{1}$, S. E. Shaker ${ }^{1}$, M. S. Afifi ${ }^{3} *$ \\ ${ }^{1}$ Department of Therapeutic Chemistry National Research Centre, Cairo, Egypt. \\ ${ }^{2}$ Department of Phytochemistry and Plant Systematics, National Research Centre, Cairo, Egypt. \\ ${ }^{3}$ Department of Pharmacognosy, Faculty of Pharmacy, Misr International University, Cairo, Egypt.
}

\begin{tabular}{ll}
\hline ARTICLE INFO & ABSTRACT \\
\cline { 3 - 4 } $\begin{array}{l}\text { Article history: } \\
\text { Received on: } 14 / 08 / 2016 \\
\text { Accepted on: } 13 / 11 / 2016 \\
\text { Available online: } 30 / 05 / 2017\end{array}$ & $\begin{array}{l}\text { The extract of Morus macroura (mulberry) fruits was evaluated for its phytochemical constituents and } \\
\text { antigastric ulcer activity. Total phenolic content was assessed and found to be } 33 \mu \mathrm{g} / \mathrm{ml} \text { expressed as mg gallic } \\
\text { acid equivalents per gram of dried extract. The phenolic profile was determined by reversed phase high } \\
\text { performance liquid chromatography coupled to diode array detection method (RP/HPLC/DAD). Cinnamic acid } \\
\text { derivatives were the most dominant (40.50\%) of the identified phenolics and chlorogenic acid was the most } \\
\text { abundant with relative area percentage } 21.16 \% \text {. Mono and disaccharides contents of the silylated-lyophilized } \\
\text { Key words: }\end{array}$ \\
$\begin{array}{ll}\text { Morus macroura, Phenolic } \\
\text { profile, gastric ulcer, } \\
\text { biochemical evaluation. }\end{array}$ & $\begin{array}{l}\text { was conducted to evaluate the antiulcerogenic effect of the extract in rats ethanol model. The reductions in } \\
\text { ulcer indices including number of lesions and their severity, the gastric volume and the total acidity in ulcerated } \\
\text { rats pre or post treated with mulberry extract were measured. A significant increase in reduced glutathione level } \\
\text { and a reduction in malondialdehyde were recorded in mulberry treated groups. In addition two ulcer biomarkers } \\
\text { prostaglandin E2 and tumor necrosis factor- } \alpha \text { showed an improvement in their levels due to mulberry } \\
\text { supplementation. Accordingly, this study recommends mulberry as an antiulcer agent. }\end{array}$ \\
\hline
\end{tabular}

\section{INTRODUCTION}

Peptic ulcers are the most common gastrointestinal disorder that occurs in clinical practice and is currently considered as a progressive global health problem. An imbalance between aggressive and protective factors in the stomach is the main reason for ulcer in gastrointestinal system (Laine et al., 2008). The pathogens of gastric ulcer are results of oxidative stress, inflammation and apoptosis accompanied by ulceration. A need for less harmful compounds of natural sources is a must, since chemical synthetic drugs exhibit many side effects. For centuries, herbals have been used traditionally for the treatment of a wide range of diseases, including gastrointestinal disorders (Safavi et al., 2015; Tarique et al., 2016). Plant-derived substances have recently become of great interest owing to their

\footnotetext{
* Corresponding Author

Manal S. Afifi*, Faculty of Pharmacy, Misr International University,

KM 28 Cairo-Ismailia Road, Cairo, Egypt, Tel: +201222305929,

+2024772033,Email: manalafifi @ hotmail.com
}

wide spread applications (Cragg and Newman, 2013; Hussain et al., 2015). Medicinal plants are considered as a rich supply and valuable source for pharmaceutical intermediates and chemical entities for synthetic drugs (Lahlou, 2013). They can also be used as nutraceuticals and food supplements (Nasri et al., 2014). Morus is a genus of flowering plants belonging to family Moraceae which comprises 10-16 species of deciduous trees commonly known as mulberries. The mulberry fruit is a multiple fruit growing wild and under cultivation in many temperate world regions (Suttie, 2012). Before maturation fruits are white, green, or pale yellow. Some of mature berry species remain white, while others turn pink and then red while ripening, then dark purple or black. A sweet flavor is a common characteristic for all species of this family when fully ripe. Mulberry trees (Morus macroura) are native to Pakistan and the present study was carried out on the fully matured completely ripen dark purple fruits cultivated in Egypt. Mulberry fruits extract (MFE) was reported to contain valuable bioactive compounds such as flavonoids, phenolic acids which acts as free radical scavengers and showed potential health benefits (Ozcan et al., 2014; Grajek et al., 2015; Skrovankova et al., 2015; Zhang et al. 2008). 
In addition to the sweet taste, functional food value and consumer's acceptance ranked mulberry as a valuable herbal remedy (Cordinunsi et al., 2005; Reganold et al., 2010). Polyphenolics and flavonols are the most common compounds in herbs with strong antioxidant and hence showed antiinflammatory activity (Farzaei et al., 2015 a, b), antiatherosclerotic, antibacterial and antiviral activities to a greater or lesser extent (Romier et al., 2009; Daglia, 2012; Cardona et al., 2013; Wasek et al., 2015).

To the best of our knowledge, the efficacy of Mulberry as a treatment for gastric ulcer has not been investigated. Since gastric ulcer is considered as an inflammatory disease two related biomarkers prostaglandin E (PGE2) and tumor necrosis factor- $\alpha$ (TNF- $\alpha$ ) have been measured. In addition, the number of lesions produced by ethanol induction and their severity as well as the gastric juice volume and their acidity were determined to measure the degree of ulceration. Besides, antioxidant biomarkers as nitric oxide (NO), reduced glutathione (GSH) and lipid peroxidation (LPO) have been measured. In the present study we aimed to determine the phytochemical constituents, total phenolic content, phenolic profile and sugar contents as well as to measure the effect of Morus macroura fruit extract (MFE) on some biochemical parameters affected by gastric ulcer to find out whether it could be ranked as an antiulcer or not.

\section{MATERIAL AND METHODS}

\section{Chemicals}

All chemicals used in the present study were of high analytical grade, products of Sigma (USA), Merck (Germany), Fluka (Switzerland) and El Nasr Company (Egypt). FolinCiocalteu reagent was obtained from Dinâmica ${ }^{\circledR}$ (Diadema, Brazil). Gallic acid, gentisic acid, ortho and para coumaric acid, vanillic acid, ferulic acid, (+)-catechin and Bis (trimethylsilyl) trifluoroacetamide (BSTFA) trimethylchlorosilane (TMCS) were purchased from Sigma-Aldrich $^{\circledR}$, (Steinheim, Germany). Caffeic acid was obtained from Merck (Darmstadt, Germany) where as Ranitidine (Zantac) was obtained from GlaxoSmithKline (GSK) SAE, Cairo- ARE. Commercial kit for NO determination (Cayman Chemical Co., Mich, and USA); ELISA Kit for the determination of TNF- $\alpha$ (Biosource ${ }^{\circledR}$, Camarillo, CA, USA) and an ELISA kit for measuring Prostaglandin $\mathrm{E}_{2}$ level (Cayman Chemical, Ann Arbor, MI, USA) were used.

\section{General experimental procedures}

Shimadzu UV 240 (P/N 204-58000) was used for the determination of total phenolic compounds. HPLC analysis was performed by reversed phase diode array detection method (RP/HPLC/DAD) (hewlett Pachard 1050) using a column Alltima C18, $5 \mu \mathrm{m}(150 \mathrm{~mm} \times 4.6 \mathrm{~mm}$ id) with a guard column Alltima C18, $5 \mu \mathrm{m}$ (Alltech). The solvent system used was a gradient of $\mathrm{A}$ $\left(\mathrm{CH}_{3} \mathrm{COOH} 2.5 \%\right), \mathrm{B}\left(\mathrm{CH}_{3} \mathrm{COOH} 8 \%\right), \mathrm{C}$ (acetonitrile). The best separation was obtained with the following gradient: at $0 \mathrm{~min}, 5 \%$ $\mathrm{B}$; at $20 \mathrm{~min}, 10 \% \mathrm{~B}$; at $50 \mathrm{~min}, 30 \% \mathrm{~B}$; at $55 \mathrm{~min}, 50 \% \mathrm{~B}$; at 60 min, $100 \% \mathrm{C}$. The solvent flow rate was $1 \mathrm{ml} / \mathrm{min}^{-1}$. Injected volume was $10 \mu \mathrm{l}$. GC/MS analysis was performed using a Thermo Scientific, Trace GC Ultra / ISQ Single Quadrupole MS, TG-5MS fused silica capillary column $(30 \mathrm{~m}, 0.251 \mathrm{~mm}, 0.1 \mathrm{~mm}$ film thickness). For GC/MS detection, an electron ionization system with ionization energy of $70 \mathrm{eV}$ was used, helium gas was used as the carrier gas at a constant flow rate of $1 \mathrm{~mL} / \mathrm{min}$. The injector and MS transfer line temperature was set at $280^{\circ} \mathrm{C}$. The oven temperature was programmed at an initial temperature $85^{\circ} \mathrm{C}$ (hold $10 \mathrm{~min}$ ) to $310^{\circ} \mathrm{C}$ as a final temperature at an increasing rate of $3^{\circ} \mathrm{C} / \mathrm{min}$ (hold $5 \mathrm{~min}$ ). From the silylated mixture, the volume injected was $1 \mu \mathrm{l}$. A glass-teflon tube (Janke \& Kunkel, IKAWERK, Germany) was used for preparation of tissue homogenate.

\section{Plant collection}

The fully matured completely ripen Morus macroura fruits were freshly collected in April 2014 from Cairo-Alexandria road at $58 \mathrm{~km}$. The fruits were dark purple with sweet palatable taste and aroma. They were identified by Dr. Mona M. Marzouk, associate professor, department of phytochemistry and plant systematics, National Research Centre, Cairo, Egypt. A voucher specimen (M83) had been deposited in the herbarium of National Research Centre, Cairo, Egypt. fresh fruits were into pieces, freeze dried and kept at $4^{\circ} \mathrm{C}$ until use.

\section{Preparation of the mulberry fruit extract}

The mulberry fruits were exhaustively extracted in soxhlet apparatus with $80 \%$ ethanol. The extract (MFE) was dried under vacuum at $40{ }^{\circ} \mathrm{C}$, lyophilized and kept refrigerated until further use. For biological studies, the extract was freshly prepared as a suspension in distilled water before use.

\section{Preparation of the silylated extract for determination of mono and disaccharides}

Mixture of TMCS $(100 \mu \mathrm{L})$ and BSTFA $(200 \mu \mathrm{L})$ were added to $5 \mathrm{mg}$ of the lyophilized MFE, vortexed in screw cap glass tubes and consecutively placed in a water bath at $80{ }^{\circ} \mathrm{C}$ for $1 \mathrm{~h}$ (Herborne, 1998).

\section{Animals}

Disease-free Sprague-Dawley male rats (150-200g) and their standard commercial feed pellets were purchased from the Experimental Animal house, National Research Center, Cairo, Egypt. Animals were housed in cages with mesh bottoms to prevent coprophagia in an air-conditioned room with a 12-h darklight cycle and were allowed free access to water and food. Rats were caged in groups and left for one week as acclimatization period.

\section{Ethics}

All experiments were carried out according to recommendation of the ethical conditions approved by the Ethics Committee of National Research Center of Experimental Animals (Ethics number 13163) which is matched with international ethics for handling of experimental animals. Animals maintenance and 
handling was done according to the National Institutes of Health Guide for Care and Use of Laboratory Animals. They were allowed to acclimate to the animal quarters and were given free access to a standard laboratory diet and water for 1 week before study.

\section{Phytochemical screening}

Plant sample was tested for the presence of carbohydrates, sterols, triterpenes, phenolics, flavonoids, alkaloids, anthraquinones, tannins and coumarins (Jyothiprabha and Venkatachalam, 2016).

\section{Determination of total phenolic compounds}

Total phenolic compounds (TPC) were determined by colorimetric assay, using the Folin-Ciocalteu reagent (Antolovich et al., 2002). Gallic acid was used as the standard reference and results were expressed as mg of gallic acid equivalents per gram of dried extract.

\section{Determination of phenolic profile}

The phenolic profile was determined by RP/HPLC/DAD method. The qualitative determination was performed using the external standard method.

\section{Doses and route of administration}

For ulcer induction, rats were fasted for $24 \mathrm{~h}$ before starting the experiments. Rats received a single dose of absolute ethanol $(5 \mathrm{ml} / \mathrm{kg})$ by oral gavage (Moustafa et al., 2013). Ranitidine as a reference antiulcer drug was orally administrated at a dose of $100 \mathrm{mg} / \mathrm{kg}$ daily for 1 week either before ulcer induction in prophylactic group or after in therapeutic group (Mard et al., 2008). The same route of administration was followed for MFE with a dose of $300 \mathrm{mg} / \mathrm{kg}$ daily.

\section{Experimental groups}

The rats were randomly divided into 2 main groups: prophylactic groups (from group 2-4) and treated groups (from group 5-7), 10 rats per each group. The first group served as negative control in which the animals received only saline. In the prophylactic ulcer control (group 2) the rats recieved absolute ethanol and sacrificed after 2 hours. The reference drug ranitidine in the prophylactic study (group 3) was administered one week before ethanol induction then sacrificed after 2 hours. Normal healthy rats administered MFE for 1 week (group 4). At day 7 the rats were ulcerated with ethanol and sacrificed 2 hours later. Rats in group 5, the positive treated control, received ethanol once and maintained for a week on saline. Ranitidine and MFE (groups 6 and 7 respectively) were administrated daily at the doses mentioned for one week after ulceration.

\section{Anesthesia}

Rats were anesthetized in a jar with a tight-fitting lid containing an appropriate amount of ether. The rat's abdomen was dissected and the esophagus nearest to the cardia and the distended stomach on the pyloric sphincter was immediately tied in a knot using a string to avoid leakage of the gastric contents (Shu et al., 2013). The stomach was rapidly removed and immersed in water.

\section{Measurement of gastric secretion}

The stomach juice containing food particles was discarded. The amount of gastric-juice was measured immediately after opening of the animal. The total acid concentration was determined in the supernatant by titration to $\mathrm{pH} 7$ with $0.01 \mathrm{~N}$ $\mathrm{NaOH}$ using phenolphthalein as indicator (Guedes et al., 2008).

\section{Quantification of ulceration}

The glandular portion comprised of the fundic and corpus region of each stomach was opened longitudinally along the greater curvature and examined macroscopically using a magnifying lens. The number and severity of lesions in the glandular mucosa were scored from 0 to 5 according to the method of Clementi et al., (1998).

\section{Preparation of tissue homogenate}

Longitudinal sections weighting $0.5 \mathrm{~g}$ from each stomach were homogenized in phosphate buffered saline $(\mathrm{pH} 7.4)$ using a glass-teflon homogenizing tube. The homogenate was centrifuged at $3000 \mathrm{rpm}$ for $10 \mathrm{~min}$ and the supernatant was stored for further estimation of the different parameters.

\section{Oxidative stress markers}

GSH levels of gastric tissue were determined by Ellman's reaction using 5'5'-dithio-bis-2-nitrobenzoic acid (DTNB) and the intensity of the yellow colour was read at $412 \mathrm{~nm}$ (Faure and Lafond, 1995). MDA was determined as an indicator of lipid peroxidation (Buege and Aust, 1978) where as NO concentration was estimated using a commercial kit according to the manufacturer's instructions.

\section{Determination of the biomarkers PGE2 and TNF- $\alpha$}

TNF- $\alpha$ expressed as $\mathrm{pg} / \mathrm{mg}$ protein and PGE2 levels in tissue homogenate were determined according to Mysliwska et al. (1998), using ELISA Kits following the instructions of the manufacturer.

\section{Statistical analysis}

The results were presented as mean \pm standard error (S.E.) and were analyzed statistically by one way analysis of variance (ANOVA) using SPSS (Statistical Package for the Social Sciences, version 9) software. Differences were considered statistically significant at $\mathrm{P}<0.05$.

\section{RESULTS}

\section{Phytochemical screening}

Preliminary phytochemical analysis of the MFE was carried out and the results showed the presence of phenolics, 
tannins, coumarins, carbohydrates, sterols, triterpenes. Flavonoids and alkaloids were detected in minute amounts where as anthraquinones could not be detected.

\section{Total phenolic content and phenolic profile}

Total phenolic content (TPC) was found to be $33 \mu \mathrm{g} / \mathrm{ml}$ expressed as mg gallic acid equivalents per gram of dried extract. RP/HPLC/DAD analysis of MFE revealed the presence of twentytwo phenolic compounds (Table 1). Seventeen phenolic acid derivatives which are among the most important non-vitamin antioxidant phytochemicals were detected. Nine of them are of cinnamic acid derivatives and eight are belonging to benzoic acid derivatives, whereas two compounds of hydroxy benzene, two flavanols and one coumarin were identified with area percentages $40.50,34.21,15.68,8.84,0.75 \%$ respectively, relative to the identified phenolics.

The cinnamic acids were the dominant compounds in the phenolic profile of the MFE where the most abundant phenolic acid was chlorogenic with a relative area percentage $21.16 \%$ followed by the benzoic acid derivative namely protocatechuic acid with $11.26 \%$. The relative area percentage and retention times of identified phenolic compounds in MFE are presented in figure 1 and table 1 and are shown in the order of their retention time.

Table 1: HPLC analyses of phenolic constituents of Mulberry fruits extract (MFE)

\begin{tabular}{cccc}
\hline No. & Phenolic compound & RR $_{\mathbf{t}}$ & *Area \% \\
\hline 1. & Gallic & 0.76 & 2.486 \\
2. & Pyrogallol & 0.79 & 2.159 \\
3. & 4- aminobenzene & 0.89 & 0.979 \\
4. & Protocatechuic & 0.92 & $\mathbf{4 . 3 1 8}$ \\
5. & Catechin & 0.93 & 2.485 \\
6. & Chlorogenic & 1 & $\mathbf{8 . 1 2 0}$ \\
7. & Catechol & 1.02 & 3.859 \\
8. & Epicatechin & 1.07 & 0.916 \\
9. & p-hydroxy benzoic & 1.08 & 1.446 \\
10. & Caffeic & 1.12 & 1.457 \\
1. & Vanillic & 1.17 & 1.270 \\
12. & p-coumaric & 1.29 & 2.489 \\
13. & Ferulic & 1.32 & 0.865 \\
14. & Iso-ferulic & 1.36 & 1.456 \\
15. & E-vanillic & 1.42 & 0.457 \\
16. & Ellagic & 1.45 & 1.247 \\
17. & $\alpha$-Coumaric & 1.49 & 1.210 \\
18. & Benzoic & 1.53 & 0.501 \\
19. & Salicylic & 1.56 & 0.423 \\
20. & 3,4,5. methoxy cinnamic & 1.58 & 0.445 \\
21. & Coumarin & 1.60 & 0.285 \\
22. & Cinnamic & 1.73 & 0.367 \\
\hline
\end{tabular}

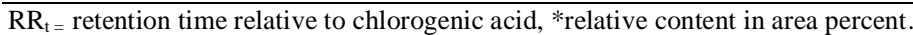

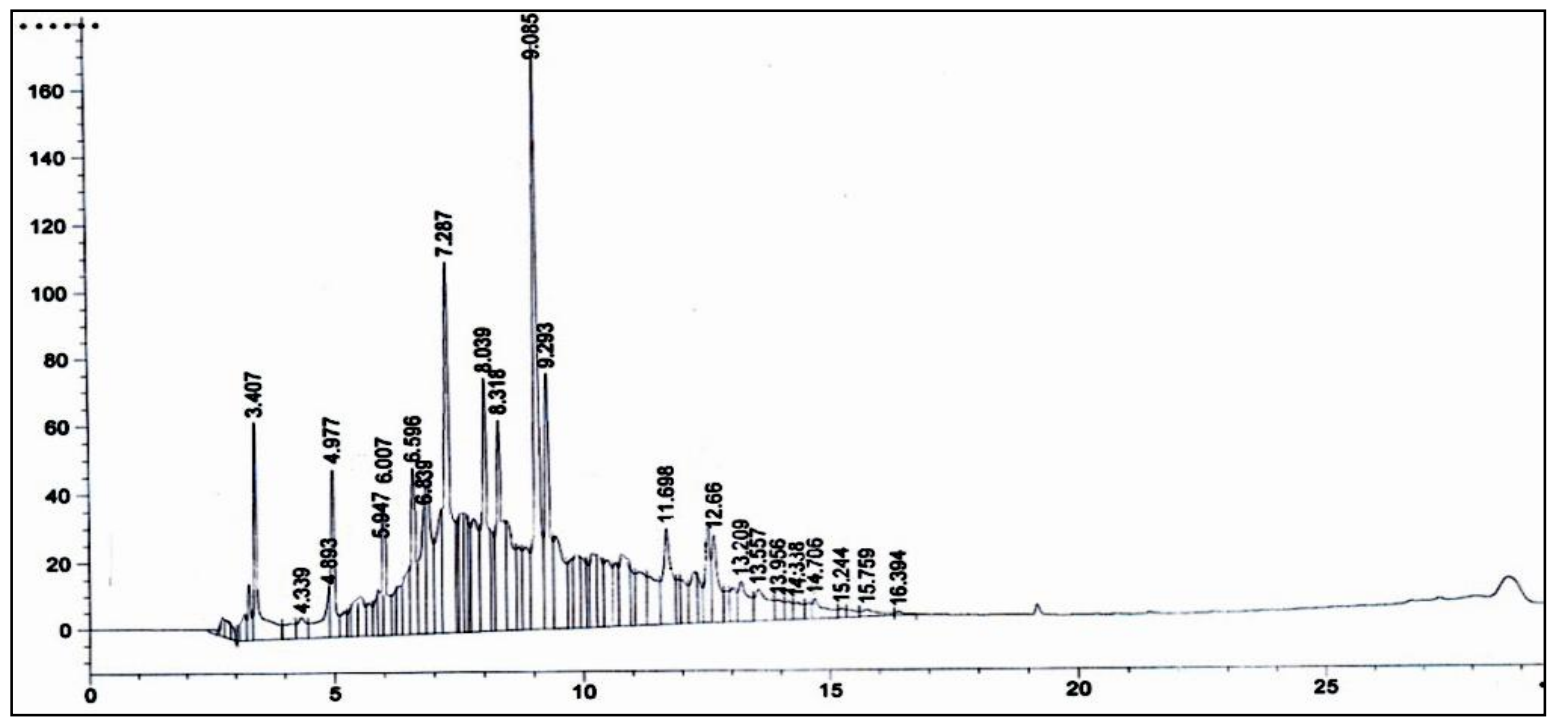

Fig. 1: HPLC Chromatogram of phenolic constituents of Mulberry Fruits extract (MFE). 


\section{GC/MS of lyophilized water-soluble silylated fraction}

GC/MS analysis of the silylated water extract of MFE revealed the presence of eighteen sugars (Table 2). The major sugars were found to be $\alpha$-D-glucofuranose, glucopyranose, D(-) fructofuranose, 1,5-anhydro-D-sorbitol, $\alpha$-D-(+) mannopyranose, mannonic acid and $\mathrm{D}(-)$ ribofuranose with the relative area percentages $32.34,16.57,15.82,9.02,6.18,5.21$ and 4.25 , respectively.

Table 2: GC/MS of lyophilized water-soluble silylated fraction of Mulberry fruits extract (MFE)

\begin{tabular}{|c|c|c|c|}
\hline No. & Name of compound & $\mathrm{RR}_{\mathrm{t}}$ & $*$ Area\% \\
\hline 1. & Glycerol, 3TMS ether & 0.38 & 0.53 \\
\hline 2. & D-Erythro- Pentofuranose, 2deoxy 3TMS & 0.85 & 0.85 \\
\hline 3. & Mannonic acid, 4TMS LACTONE & 0.86 & 5.21 \\
\hline 4. & 1,5-Anhydro-D-sorbitol, 4TMS ether & 0.878 & 9.02 \\
\hline 5. & L (-)Sorbofuranose, 5TMS ether & 0.90 & 0.05 \\
\hline 6. & D (-)Fructofuranose, 5TMS ether & 0.91 & 15.82 \\
\hline 7. & $\alpha$-D- Glucofuranose methyl, 4 TMS & 1 & 32.34 \\
\hline 8. & 2-Deoxygalactose 4TMS & 1.02 & 1.60 \\
\hline 9. & $\alpha$-D-Allopyranose, 5 TMS ether & 1.034 & 3.04 \\
\hline 10. & $\alpha$-D-Mannopyranose, methyl 4 TMS & 1.045 & 6.18 \\
\hline 11. & $\alpha-\mathrm{D}-(+)$-Talopyranose, 5 TMS & 1.046 & 2.38 \\
\hline 12. & Ribitol,5 TMS & 1.049 & 0.26 \\
\hline 13. & $\alpha$-D-Xylopyranose, 4TMS ether & 1.054 & 0.72 \\
\hline 14. & D (-)Ribofuranose, 4 TMS ether & 1.058 & 4.25 \\
\hline 15. & D (+) Talofuranose, 5 TMS ether & 1.06 & 0.53 \\
\hline 16. & Glucopyranose 5TMS & 1.077 & 16.57 \\
\hline 17. & $\alpha$-D-Fructose, 1 deoxy-1-piperidino-4TMS) & 1.22 & 0.37 \\
\hline 18. & Sucrose TMS & 1.39 & 0.05 \\
\hline
\end{tabular}

$\mathrm{RR}_{\mathrm{t}}=$ retention time relative to Glucofuranose, *relative content in area percent

\section{Toxicity of Mulberry Fruit extract}

MFE was investigated for acute toxicity in mice. Two single oral doses (200 and $500 \mathrm{mg} / \mathrm{kg}$ ) did not produce any visible signs or symptoms of toxicity in the treated animals. Accordingly, it was promising to go on this study.

\section{Gastric ulcer indices}

Ethanol induction showed significant changes in ulcer indices in non-treated rats (Fig.2). The highest number of lesions and the greatest severity were found in the non treated rats sacrificed two hours after ethanol injection. These data were parallel to that of the total acidity which is a measure of $\mathrm{H}^{+}$ content, where the highest level was measured in the same group (Fig.3). An improvement in the number of lesions and their severity were noticed one week after ulceration without any treatment; however the total acidity was still high. Post treatment with MFE showed the best recovery in the three parameters among all other groups, even better than the reference drug ranitidine group.

Post treatment with either MFE or ranitidine showed better recovery in these parameters when compared to their correspondent pre-treated groups. Similar results were found in gastric juice volume in all groups. However, the post treatment with MFE induced the best recovery.

\section{Antioxidant levels}

The antioxidant parameters LPO and GSH showed parallel changes as did the ulcer indices (Fig.4). A high increase in MDA and a decrease in GSH concentration were measured in both pre- and post-non treated ulcer control. MFE post treatment induced the best recovery degree with results better than ranitidine. Although the number of lesions in the post non-treated control was reduced, but MDA level was not reduced to the level of negative control group.

A recovery in GSH level was found in all groups whereas MFE post-treated group showed the best recovery level. A high decrease in NO level was measured in the tissue homogenates of the pre-treated control group. The results showed that MFE post treatment was ranked as the best ameliorated one.

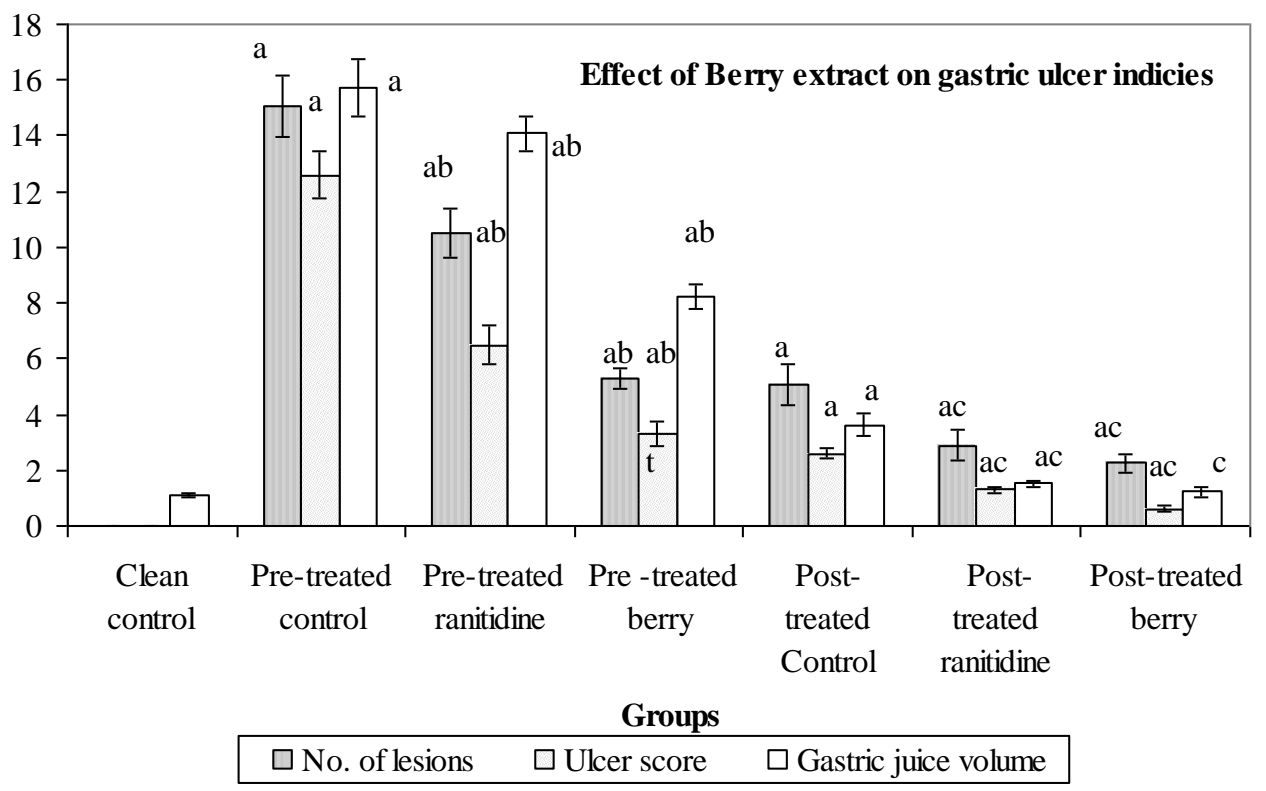

Fig. 2: Effect of Berry (MFE) extract on No. of lesions, ulcer score and gastric juice volume. Data are mean \pm SE of eight mice in each group. Gastric volume is expressed as mean $\mathrm{x} 100$ in $\mu 1$, ${ }^{\mathrm{a}} \mathrm{P}<0.05$ compared to clean control group and ${ }^{\mathrm{b}} \mathrm{P}<0.05$ compared to ulcer control group(prophylactic) and ${ }^{\mathrm{c}} \mathrm{P}<0.05$ compared to ulcer control group (post treated). 


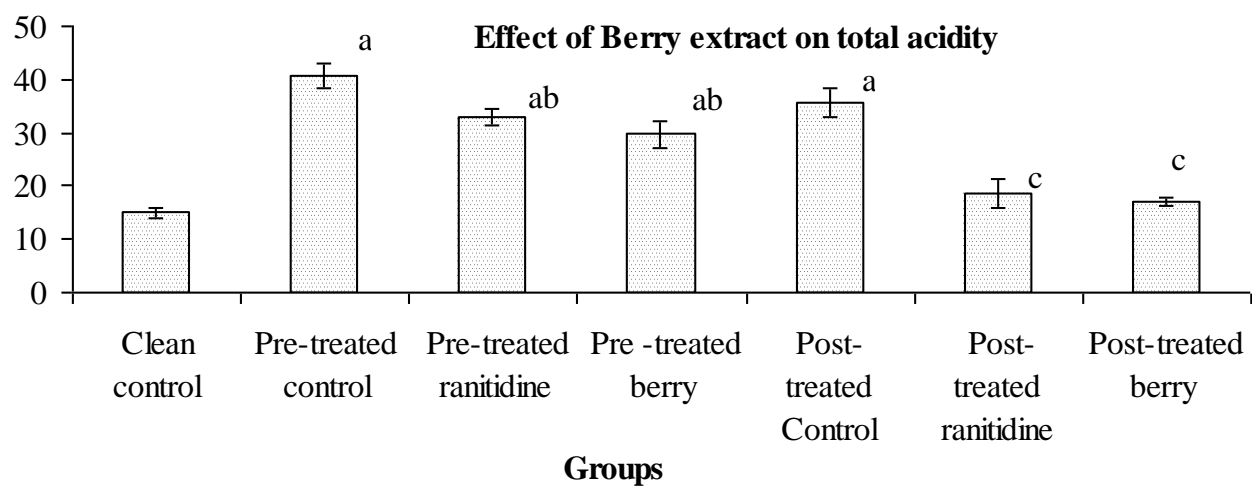

\section{$\square$ Total acidity}

Fig. 3: Effect of Berry (MFE) extract on total acidity. Data are mean \pm SE of eight mice in each group. Gastric volume is expressed in $\mu 1$, ${ }^{a} \mathrm{P}<0.05$ compared to clean control group and ${ }^{\mathrm{b}} \mathrm{P}<0.05$ compared to ulcer control group(prophylactic) and ${ }^{\mathrm{c}} \mathrm{P}<0.05$ compared to ulcer control group (post treated).

Effect of Berry extract on oxidative stress and antioxidative markers in tissue

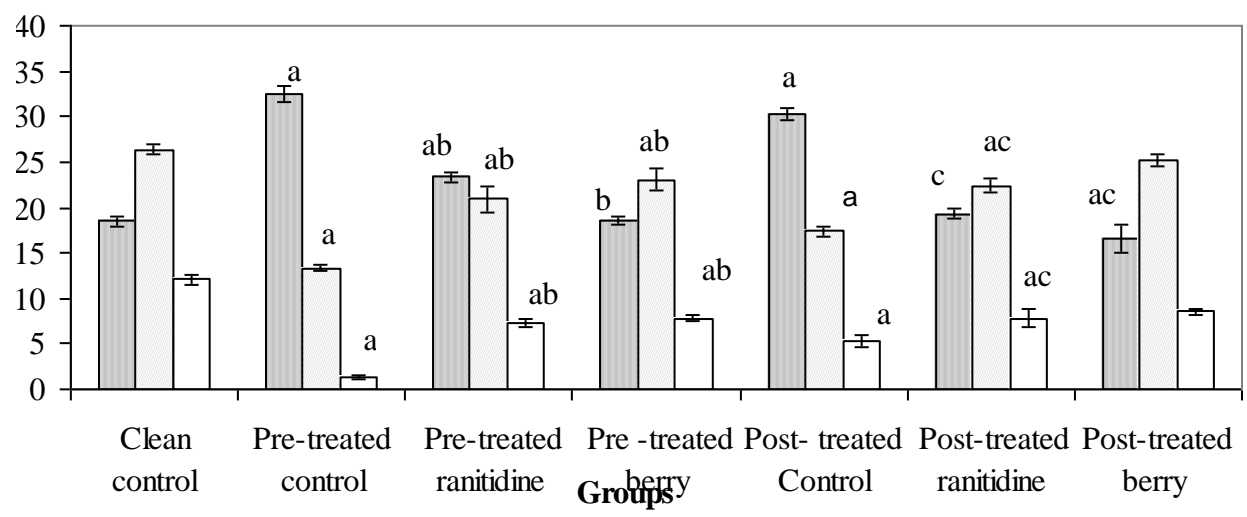

\section{$\square$ Malondialdehyde $\quad \square$ Glutathione $\quad \square$ NO}

Fig. 4: Effect of Berry (MFE) extract on oxidative stress and antioxidative markers in tissue. Data are means \pm SE of eight rats in each group; data are expressed as $\mu \mathrm{g} / \mathrm{g}$ tissue for glutathione, $\mathrm{nmol} / \mathrm{g}$ tissue for malondialdehyde, $\mu \mathrm{mol} / \mathrm{g}$ tissue for $\mathrm{NO}$ (mean $\mathrm{x} 100$ ), ${ }^{\mathrm{a}} \mathrm{P}<0.05$ compared to clean control group and ${ }^{\mathrm{b}} \mathrm{P}<0.05$ compared to ulcer control group (prophylactic) and ${ }^{\mathrm{c}} \mathrm{P}<0.05$ compared to ulcer control group (post treated).

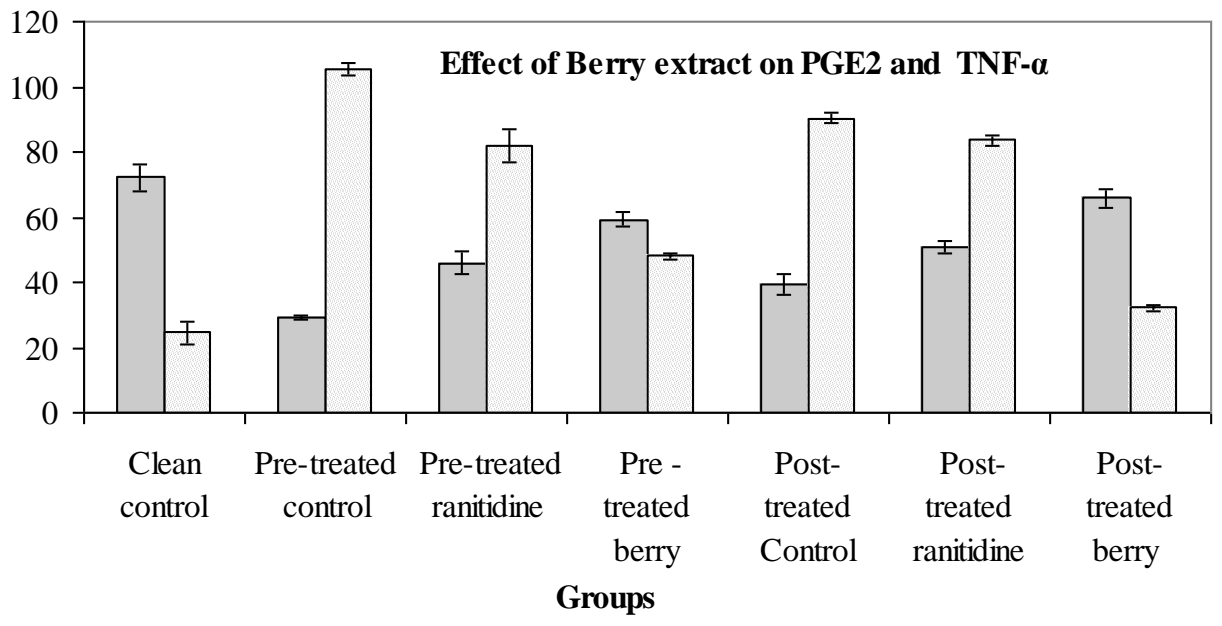

\section{$\square$ PGE2 $\square$ TNF- $\alpha$}

Fig. 5: Effect of Berry (MFE) extract on PGE2 and TNF- $\alpha$. Data are means \pm SE of eight rats in each group; data are expressed as ng/g tissue for PGE 2 and pg/g tissue for TNF $\alpha, \quad{ }^{a} \mathrm{P}<0.05$ compared to clean control group and ${ }^{\mathrm{b}} \mathrm{P}<0.05$ compared to ulcer control group (prophylactic) and ${ }^{\mathrm{c}} \mathrm{P}<0.05$ compared to ulcer control group (post treated). 


\section{Levels of biomarkers PGE-2 and TNF- $\alpha$}

Different degrees of amelioration in TNF were detected in all treated groups. The control pre-treated ulcerated group exhibited the highest increase in the TNF- $\alpha$ (Fig 5). MFE post treated group showed the best recovery followed by MFE prophylactic one. Similar results, but in a decreasing mode, were registered in the level of PGE-2 (Fig 5). MFE post treatment corrected the decrease in PGE-2 level due to ulceration much greater than all other groups. Even the used reference drug failed to reach the same improvement.

\section{DISCUSSION}

Polyphenolics in human diet are potent antioxidants and have demonstrated beneficial influence on human health (Williamson and Manach, 2005). A direct relationship between high intake of phenolic compounds with diet and reduced risk of degenerative diseases has been reported in epidemiological studies. This was attributed to the antioxidant activity of phenols to protect cell constituents from produced free radicals and hence reduces the risk of different degenerative diseases due to oxidative stress (Zhang et al., 2015). The antioxidant potency of the phenolic compounds depends on the number of hydroxyl groups and on the stabilization of the radical formed through an increased electron delocalization. Introduction of second hydroxyl group increases the antioxidant activity and hence the activity of protochatechuic and gallic acids. Cinnamic acids contain an ethenyl moiety which ensures higher H-donating ability and subsequent free radical scavenging ability. According to Górecka et al., (2014) chlorogenic, $p$-coumaric, caffeic and other cinnamic acid derivatives were found to be more active than benzoic acid derivatives. Since the phenolic profile of the plant is mainly constituted of chlorogenic and cinnamic acid derivatives, this potent antioxidant activity was expected. Chlorogenic, protochatechuic acids are free radical and metal scavengers and have been shown to modulate gene expression of antioxidant glycosylation enzymes (Fiuza et al., 2004). The results are in accordance with previous reports of phenolic acids contents in other mulberry species (Flaczyk, 2013).

It is not easy to suggest a specific mechanism of action for a crude extract of a natural plant as it contains thousands of elements. Accordingly, studying the effect of the extract on several parameters which could be affected in a model representing the concerned disease could help to evaluate the efficacy of the plant as a valuable medicinal one. The preliminary phytochemical screening of the MFE revealed the presence of phenolic constituents which encouraged us to determine its antiulcerogenic activity (Sumbul et al., 2011). As MFE extract did not manifest any toxic or abnormal changes even at high dose as reported by Wattanathorn et al. (2013) and proved in the experimental part. Ethanol is an ulcerogenic necrotizing agent that induces gastric hemorrhagic erosion after oral administration (Awaad et al., 2013). Ethanol also induces an imbalance in various parameters of the gastric mucosa by increasing the harmful reactive oxygen species as well as decreasing in gastric mucus, prostaglandin production and gastric mucosal blood flow (Li et al., 2016). In the present study, the control group subjected to ethanol clearly produced the expected characteristic zone of necrotizing mucosal lesions, while pre or post treatment with MFE had significantly decreased the ulcerative indices and the percentage of lesions. A reduction in number of lesions and their severity in the gastric wall, as well as the decrease in gastric juice volume and total acidity were measured in MFE treated ulcerated animals.

The results revealed that gastroprotectant (prophylactic) use of MFE accelerates the ulcer healing at the early phase of ulcer healing, but the post treatment was more effective. The greater amelioration in the different parameters measured in this study was due to MFE post treatment than pre treatment. These results indicate that MFE exhibited antiulcer activity against ethanolinduced ulcerogenesis in rats.

Free radical mediated stress has been one of the concerns in the pathogenesis of gastrointestinal disorders (Kisaoglu, 2013) therefore; the antioxidant activity of MFE has also been studied. The cytoprotective effect of GSH can be seen by comparing its level in the two control ulcerated groups, where GSH was decreased in the pre-treated more than post-treated ulcerated control, in which the animals did not receive any treatment. One week after ulceration gives the rats a chance for cytoprotection occurrence. However, GSH level did not reach the normal control value. Availability of GSH is crucial for the integrity of mucosa as it is considered as a first-line non enzymatic antioxidant defense against oxidative stress where as its depletion causes severe ulceration (Khan and Khan, 2013). Szabo et al., (1981) suggested that gastric sulfhydryl compounds, primarily GSH, are essential in gastric cytoprotection. They reported that sulfhydryl blockers reverse cytoprotection by $\mathrm{PGF}_{2 \beta}$ against absolute EtOH-induced gastric lesions. According to Kimura et al., (2001) sulfhydryl compounds in living organisms play a central role in the maintenance of gastric integrity, especially when free radicals are produced accompanying the pathogenesis of tissue damage. A significant decrease in gastric non-protein sulfhydryls appeared following ethanol administration due to enormous production of ROS (Zakaria et al., 2016). The increase in GSH level in ulcerated treated rats is accompanied with a decrease in lipid peroxidation measured by its MDA end product. A relationship between the levels of gastric mucosal LPO end products and gastric ulceration in stress induced ulcers had been reported by several authors (Ibrahim et al., 2015; Wang et al., 2015). The protective effect of MFE is obvious in improving the two antioxidant parameters bringing them almost to their normal level and better than that of ranitidine. The oxidative stress induced by ethanol sounded also in the other biochemical markers measured in this study. The present results revealed a high decrease in $\mathrm{NO}$ and $\mathrm{PGE}_{2}$ and a pronounced increase in TNF- $\alpha$ level due to ethanol induction. The gastric mucosal defense involves secretion of luminal factors such as mucus and bicarbonate, epithelial barriers and continuous blood flow through mucosal microvessels. PGs and NO modulate these factors by inhibiting acid secretion, stimulating the production of 
luminal factors, increasing blood flow and accelerating epithelial restitution (Hatazawa et al., 2006; Takeuchi and Nagahama, 2014). NO plays an important role in maintaining the integrity of the mucosa as the synthesis of mucus and bicarbonate is dependent on it. Moreover, inhibition of PGs production results in increased acid production and decreased cytoprotective mucus formation, which can lead to gastrointestinal ulceration (Nguelefack et al., 2008). Juinior et al., (2014) and Nordin et al., (2014) supported the assumption that $\mathrm{PGE}_{2}$ and $\mathrm{NO}$ share in the self protective mechanism against gastric ulcer and mucosal damage. As MFE enhances the production of both $\mathrm{PGE}_{2}$ and $\mathrm{NO}$, it powers its antiulcer activity. The present results show a time effect on the level of $\mathrm{PGE}_{2}$ when comparing the two ulcerated control group and the two MFE treatments with each other. This can be explained by the findings of Hatazawa et al., (2007) and Sakata and Yao et al., (2010) which have shown that the cytoprotective effect of $\mathrm{PGE}_{2}$ provides noteworthy resistance of gastric mucosal cells against strong irritants, including ethanol. Increasing TNF- $\alpha$ in ulcerated animals was recently measured by Pawliki et al., (2016) and are considered to be the manifestation of an inflammatory response. They also found that the ulcer recovery was accompanied with a decrease in the elevated TNF- $\alpha$. Gastric inflammation increases leukocyte adherence to the endothelial surface of postcapillary venules and is characterized by the migration of macrophages and polymorphonuclear leukocytes in the ulcer area causing the release proinflammatory mediators such as TNF- $\alpha$ (Eamlamnam et al., 2006). MFE treatment prevents this increase in TNF- $\alpha$ level.

\section{CONCLUSION}

Total phenolic content of the MFE and its phenolic profile were determined. Phenolic profile could serve as a tool to justify the geographic origin of these mulberry fruit varieties and contribute to the chemotaxonomic classifications. The study was conducted to evaluate the antiulcerogenic effect. A reduction in ulcer indices including number of lesions and their severity, the gastric volume and the total acidity in ulcerated rats pre or post treated with mulberry extract were measured. A significant increase in GSH level and a reduction in MDA were recorded. In addition PGE2 and TNF- $\alpha$ showed an improvement in their levels due to mulberry supplementation. Accordingly, our study recommends mulberry as a valuable natural drug for treatment of gastric ulcer, however further studies are needed.

\section{Financial support and sponsorship: NIL.}

Conflict of Interests: There are no conflicts of interest.

\section{REFERENCES}

Antolovich M, Prenzler PD, Patsalides E, Mc Donald S, Robards K. Methods for testing antioxidant activity. Analyst, 2002; 127(1):183- 198

Awaad AS, El-Meligy RM, Soliman GA. Natural products in treatment of ulcerative colitis and peptic ulcer. J Saud Chem Soc, 2013; 17(1):101-124.

Buege JA, Aust SD. Microsomal lipid peroxidation. Method Enzymol, 1978; 52 (C), 302-310.
Cardona F, Andrés-Lacueva C, Tulipani S, Tinahones FJ, QueipoOrtuño MI. Benefits of polyphenols on gut microbiota and implications in human health. J Nutr Biochem, 2013; 24: 1415-1422.

Clementi G, Caruso A, Cutuli VM, de Bernardis E, Prato A, Mangano NG, Amico-roxas M. Effects of centrally or peripherally injected adrenomedullin on reserpine-induced gastric lesions. Eur J pharmacol, 1998; 360(1): 51-54.

Cordenunsi BR, Genovese MI, Do-Nascimento JRO, AymotoHassimotto NM, Santos RJD, Lajolo FM. Effects of temperature on the chemical composition and antioxidant activity of three strawberry cultivars. Food Chem, 2005; 91:113-121.

Cragg GM and Newman DJ. Natural products: a continuing source of novel drug leads Biochim Biophys Acta. 2013 ; 1830 (6): 36703695 .

Daglia M. Polyphenols as antimicrobial agents. Curr Opin Biotechnol, 2012; 23: 174-181.

Eamlamnam K, Patumraj S, Visedopas N, Thong-Ngam D. Effects of Aloe vera and sucralfate on gastric microcirculatory changes, cytokine levels and gastric ulcer healing in rats. World $\mathbf{J}$ of gastroenterol, 2006;12 (13): 2034-2039.

Farzaei MH, Abdollahi M and Rahimi R. Role of dietary polyphenols in the management of peptic ulcer. World journal of gastroenterol. 2015a; 21(21): 6499-6517.

Farzaei MH, Rahimi R, Abdollahi M. The role of dietary polyphenols in the management of inflammatory bowel disease. Curr Pharm Biotechnol, 2015b; 16: 196-210.

Faure P, Lafond JL. Measurement of plasma sulfhydryl and carbonyl groups as a possibleindicator of protein oxidation. Analysis of free radicals in biological systems. Birkäuser, Basel; Boston, Berlin, 1995; 237-248

Fiuza SM, Gomes C, Teixeira LJ, Da Cruz MG, Cordeiro MN, Milhazes N, Borges F, Marques MP. Phenolic acid derivatives with potential anticancer properties-a structure-activity relationship study. Part 1: Methyl, propyl and octyl esters of caffeic and gallic acids. Bioorg \& med chem, 2004; 12(13):3581-3589.

Flaczyk E, Kobus-Cisowska J, Przeor M, Korczak J, Remiszewski M, Korbas E, Buchowski M. Chemical characterization and antioxidative properties of Polish variety of Morus alba L. leaf aqueous extracts from the laboratory and pilot-scale processes. Agri Sci, 2013; 4(5B):141-147.

Górecka AK, Stojko AR, Górecki M, Stojko J, Sosada M and Zięba GŚ. Structure and Antioxidant Activity of Polyphenols Derived from Propolis. Molecules, 2014; 19: 78-101.

Grajek K, Wawro A and Kokocha D. Bioactivity of Morus alba 1. Extracts-An overview. Int J Pharm Sci Res, 2015; 6(8): 3110-3122.

Guedes MM, Carvalho AC, Lima AF. Gastroprotective mechanisms of centipedic acid, anatural diterpene from Egletes viscosa LESS. Biol Pharm Bull Jul, 2008; 31(7): 1351-1355.

Hatazawa R, Ohno R, Tanigami M, Tanaka A and Takeuchi K. Roles of endogenous prostaglandins and cyclooxygenase isozymes in healing of indomethacin-induced small intestinal lesions in rats. J Pharmacol Experm Therap, 2006; 318(2), 691-699.

Hatazawa R, Tanaka A, Tanigami M, Amagase K, Kato S, Ashida Y, Takeuchi K. Cyclooxygenase-2/prostaglandin E2 accelerates the healing of gastric ulcers via EP4 receptors. Am J Physiol Gastrointest Liver Physiol, 2007; 1:293(4):G788-797.

Herborne JB. Phytochemical methods, A guide to modern techniques of plant analysis. Chapman and Hall London, 1998; 1:135.

Hussain L, Akash MS, Naseem S, Rehman K, Ahmed KZ . Anti-Ulcerogenic Effects of Salmalia Malabarica in Gastric UlcerationPilot Study. Adv Clin Exp Med. 2015 ; 24(4):595-605.

Ibrahim IA, Abdulla MA, Hajrezaie M, Bader A, Shahzad N, Al-Ghamdi SS, Gushash AS, Hasanpourghadi M. The gastroprotective effects of hydroalcoholic extract of Monolluma quadrangula against ethanol-induced gastric mucosal injuries in Sprague Dawley rats. Drug Des Devel Ther, 2015; 10: 93-105.

Júnior FE, de Oliveira DR, Boligon AA, Athayde ML, Kamdem JP, Macedo GE, da Silva GF, de Menezes IR, Costa JG, Coutinho HD, Kerntopf MR. Protective effects of Croton campestris A. St-Hill in 
different ulcer models in rodents: evidence for the involvement of nitric oxide and prostaglandins. J ethnopharmacol, 2014; 153(2):469-477.

Khan MI and Khan MR. Gastroprotective potential of Dalbergia sissoo roxb. stem bark against diclofenac-induced gastric damage in rats. Osong Pub Health Res Perspect, 2013; 4(5), 271-277

Kimura M, Goto S, Ihara Y, Wada A, Yahiro K, Niidome T, Aoyagi H, Hirayama T, Kondo T. Impairment of glutathione metabolism in human gastric epithelial cells treated with vacuolating cytotoxin from Helicobacter pylori. Microbial pathogenesis, 2001; 31(1):29-36.

Kisaoglu A, Borekci B, Yapca OE, Bilen H, Suleyman H. Tissue damage and oxidant/antioxidant balance. Eurasian J Med, 2013; 45:47-49.

Lahlou M. The success of natural products in drug discovery. Pharmacol \& Pharm, 2013; 4: 17-31.

Laine L, Takeuchi K and Tarnawski A. Gastric mucosal defense and cytoprotection: bench to bedside. Gastroenterol, 2008; 135(1): 41-60.

Li W, Wang X, Zhang H, He Z, Zhi W, Liu F, Wang Y and Niu $X$. Anti-ulcerogenic effect of cavidine against ethanol-induced acute gastric ulcer in mice and possible underlying mechanism. Int Immunopharmacol, 2016; 38, 450-459.

Mard SA, Bahari Z, Eshaghi N, Farbood Y. Antiulcerogenic effect of Securigerssecuridaca L. seed extract on various experimental gastric ulcer models in rats. Pak J Biol Sci, 2008; 11: 261-23.

Moustafa YM, Khoder DM, EL-Awady DD, Zaitone AA. Sildenafil citrate protects against gastric mucosal damage induced by indomethacin in rats. Eur Rev Med Pharm Sci, 2013; 17: 179-188.

Myśliwska J, Zorena K, Bakowska A, Skuratowicz-Kubica A, Myśliwski A. Significance of tumor necrosis factor alpha in patients with long-standing type-I diabetes mellitus. Hormone and Metabolic Res, 1998; 30(3):158-161.

Nasri H, Baradaran A, Shirzad H, and Rafieian-Kopaei M . New concepts in nutraceuticals as alternative for pharmaceuticals. Int $\mathbf{J}$ Prev Med. 2014; 5(12): 1487-1499.

Nguelefack TB, Feumebo CB, Ateufack G, Watcho P, Tatsimo $\mathrm{S}$, Atsamo AD, Tane P, Kamanyi A. Anti-ulcerogenic properties of the aqueous and methanol extracts from the leaves of Solanum torvum (Solanaceae) in rats. J. ethnopharmacol, 2008; 119 (1):135-140.

Nordin N, Salama SM, Golbabapour S, Hajrezaie M, Hassandarvish P, Kamalidehghan B, Majid NA, Hashim NM, Omar H, Fadaienasab M, Karimian H. Anti-ulcerogenic effect of methanolic extracts from Enicosanthellum pulchrum (King) Heusden against ethanolinduced acute gastric lesion in animal models. PLoS One, 2014; 9(11):e111925.

Ozcan T, Bayizit AA, Ersan LY, and Delikanli B. Phenolics in Human Health. Int J Chem Eng App, 2014; 5(5): 393-396.

Pawlik MW, Kwiecien S, Ptak-Belowska A, Pajdo R, Olszanecki R, Suski M, Madej J, Targosz A, Konturek SJ, Korbut R, Brzozowski T. The renin-angiotensin system and its vasoactive metabolite angiotensin in the mechanism of the healing of preexisting gastric ulcers. The involvement of mas receptors, nitric oxide, prostaglandins and proinflammatory cytokines. J Phys. Pharm., 2016; 2:01-07.

Reganold JP, Andrews PK, Reeve JR, Carpenter-Boggs L, Schadt CW. Fruit and soil quality of organic and conventional strawberry agroecosystems. PLoS One., 2010; 5:1-14.

Romier, B., Schneider, Y.J., Larondelle, Y. and During, A. Dietary polyphenols can modulate the intestinal inflammatory response. Nutrition reviews, 2009; 67(7): 363-378.

Safavi M, Shams-Ardakani M, Foroumadi A. Medicinal plants in the treatment of Helicobacter pylori infections. Pharm Biol., 2015; 53 (7):939-960.

Sakata D, Yao C, Narumiya S. Prostaglandin E2, an immunoactive J Pharmacol Sci, 2010; 112(1):1-5.
Shu MH, Appleton D, Zandi K, and AbuBakar S. Antiinflammatory, gastroprotective and anti-ulcerogenic effects of red algae Gracilaria changii (Gracilariales, Rhodophyta) extract. BMC Complement Altern Med, 2013; 13: 61

Skrovankova S, Sumczynski D, Mlcek J, Jurikova T and Sochor J. Bioactive compounds and antioxidant activity in different types of berries. Int J Mol Sci. 2015; 16: 24673-24706.

Sumbul S, Ahmad MA, Asif Mohd., and Mohd A. Role of phenolic compounds in peptic ulcer: An overview. J Pharm Bioallied Sci. 2011;3(3): 361-367.

Suttie JM. Morus alba L. Plant Production and Protection. Food and Agricultural Organization of the United Nations. 2012.

Szabo S, Trier JS, Frankel PW. Sulfhydryl compounds may mediate gastric cytoprotection. Science, 1981; 214(4517): 200-202.

Takeuchi K and Nagahama K. Animal Model of Acid-Reflux Esophagitis: Pathogenic Roles of Acid/Pepsin, Prostaglandins, and Amino Acids. BioMed Res Int, 2014; 2014:1-10.

Tarique M, Siddiqui HH, Khushtar $M$ and Rahman MA. Protective effect of hydro-alcoholic extract of Ruta graveolens Linn. leaves on indomethacin and pylorus ligation-induced gastric ulcer in rats. $\mathbf{J}$ Ayurveda Integr Med, 2016; 7(1):38-43.

Jyothiprabha V and Venkatachalam P. Preliminary Phytochemical screening of different solvent extracts of selected indian spices. Int J Curr Microbiol App Sci, 2016; 5(2): 116-122.

Wang FY, Liu JM, Luo HH, Liu AH, Jiang Y Potential protective effects of Clostridium butyricum on experimental gastric ulcers in mice. World J Gastroenterol, 2015; 21(27):8340-8351.

Wasek M, Giebułtowicz J, Sochacka M, Zawada K, Modzelewska W, Krześniak LM, Wroczyński P. The measurement of antioxidant capacity and polyphenol content in selected food supplements. Acta Pol Pharm, 2015; 72(5):877-87.

Wattanathorn J, Thukummee W, Thipkaew C, Wannanond P, Tong-Un T, Muchimapura S and Kaewrueng W. Acute and subchronic toxicity of mulberry fruits. Am J Agri and Biol Sci, 2012; 7 (3): 378-383.

Williamson $\mathrm{G}$ and Manach C. Bioavailability and bioefficacy of polyphenols in humans. II. Review of 93 intervention studies. Am J Clin Nutr, 2005; 81:243S-55S

Zakaria ZA, Balan T, Azemi AK, Omar MH, Mohtarrudin N, Ahmad Z, Abdullah MNH, Desa MNM, Teh LK and Salleh MZ. Mechanism(s) of action underlying the gastroprotective effect of ethyl acetate fraction obtained from the crude methanolic leaves extract of Muntingia calabura. BMC complementary and alternative medicine, 2016; 16(1): 78.

Zhang Y, Seeram NP, Lee R, Feng L, Heber D. Isolation and identification of strawberry phenolics with antioxidant and human cancer cell antiproliferative properties. J agric food chem, 2008; 56(3):670-675.

Zhang YJ, Gan RY, Li S, Zhou Y, Li AN, Xu DP and Li HB. Antioxidant Phytochemicals for the Prevention and Treatment of Chronic Diseases 3. Molecules, 2015; 20: 21138-21156.

\section{How to cite this article:}

Farrag EK, Kassem MES, Bayoumi D, Shake SE and Afifi MS. Phytochemical study, phenolic profile and antigastric ulcer activity of Morus macroura Miq. fruits extract. J App Pharm Sci, 2017; 7 (05): 152-160. 